\title{
The SaeRS Two-Component System of Staphylococcus aureus
}

\author{
Qian Liu ${ }^{1}$, Won-Sik Yeo ${ }^{2}$ and Taeok Bae ${ }^{2, *}$ \\ 1 Department of Laboratory Medicine, Ren Ji Hospital, School of Medicine, Shanghai Jiao Tong University, \\ Shanghai 200127, China; qq2005011@163.com \\ 2 Department of Microbiology and Immunology, Indiana University School of Medicine-Northwest, Gary, \\ IN 46408, USA; wonyeo@iu.edu \\ * Correspondence: tbae@iun.edu; Tel.: +1-219-980-6609
}

Academic Editor: Helen J. Wing

Received: 18 August 2016; Accepted: 23 September 2016; Published: 3 October 2016

\begin{abstract}
In the Gram-positive pathogenic bacterium Staphylococcus aureus, the SaeRS two-component system (TCS) plays a major role in controlling the production of over 20 virulence factors including hemolysins, leukocidins, superantigens, surface proteins, and proteases. The SaeRS TCS is composed of the sensor histidine kinase SaeS, response regulator SaeR, and two auxiliary proteins SaeP and SaeQ. Since its discovery in 1994, the sae locus has been studied extensively, and its contributions to staphylococcal virulence and pathogenesis have been well documented and understood; however, the molecular mechanism by which the SaeRS TCS receives and processes cognate signals is not. In this article, therefore, we review the literature focusing on the signaling mechanism and its interaction with other global regulators.
\end{abstract}

Keywords: Staphylococcus aureus; Two-component system; Virulence factors; Bacterial histidine kinase

\section{Introduction}

The Gram-positive pathogen Staphylococcus aureus is a major cause of morbidity and mortality. This bacterium causes a variety of diseases ranging from soft-tissue infections to life-threatening invasive diseases such as endocarditis, toxic shock syndrome, and necrotizing pneumonia [1,2]. The success of $S$. aureus as a human pathogen is largely due to its production of multiple virulence factors, which contribute to various aspects of the bacterial pathogenesis from binding to host tissues to immune evasion [3-5]. In S. aureus, the production of virulence factors is controlled by an intricate network of transcription regulators including alternative sigma factor $\sigma^{\mathrm{B}}$, DNA binding proteins (e.g., SarA and its homologues) and two-component signaling systems (e.g., AgrAC, ArlRS, SrrAB, and SaeRS) [6-11].

The sae (S. aureus exoprotein expression) locus, which encodes the SaeRS TCS, was identified by Giraudo et al. in 1994 during their characterization of a Tn551 mutant for its defect in the production of exoproteins (e.g., $\alpha$-hemolysin, $\beta$-hemolysin, nuclease, and coagulase) $[12,13]$. As with other typical TCSs, the signaling cascade in the SaeRS TCS starts when SaeS, the sensor histidine kinase, detects cognate environmental signals (e.g., human neutrophil peptides, HNPs) [14] and autophosphorylates at the conserved His131 residue. The phosphoryl group is then transferred to Asp51 of SaeR, and the phosphorylated SaeR (SaeR-P) binds to SaeR binding sequence (SBS) and, in most cases, activates the transcription of the target genes. Due to its profound effects on staphylococcal virulence gene expression and pathogenesis, the SaeRS TCS (Sae system) has been a target of extensive research, and the roles of the TCS in virulence gene expression and staphylococcal pathogenesis are well documented and understood [15-17]. Therefore, in this article, we will review the literature focusing on the molecular mechanism of cell signaling. In addition, at the end, we will briefly discuss the 
interaction of the SaeRS TCS with other regulatory systems and its role in biofilm formation and staphylococcal virulence.

\section{Components of the SaeRS TCS}

\subsection{Structure of the sae Operon}

The sae operon consists of four genes (saeP, saeQ, saeR, and saeS), and the two promoters P1 and P3 (Figure 1) [15,18,19].

A

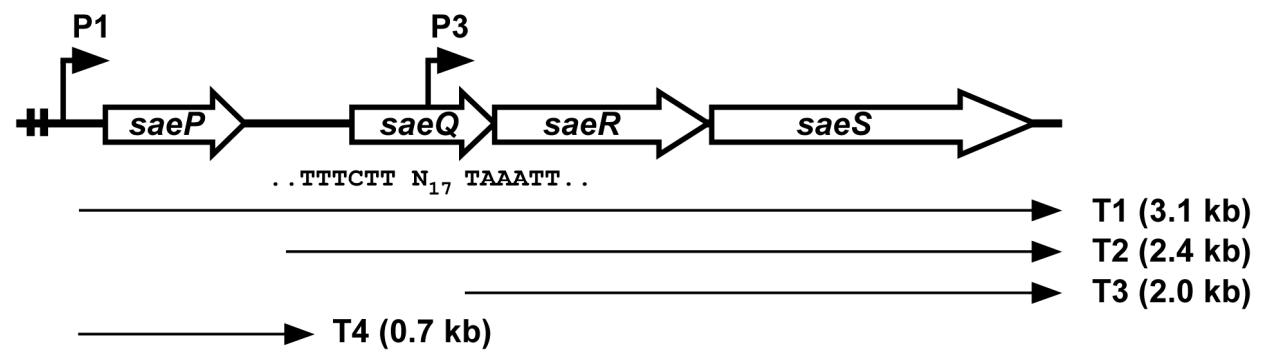

B

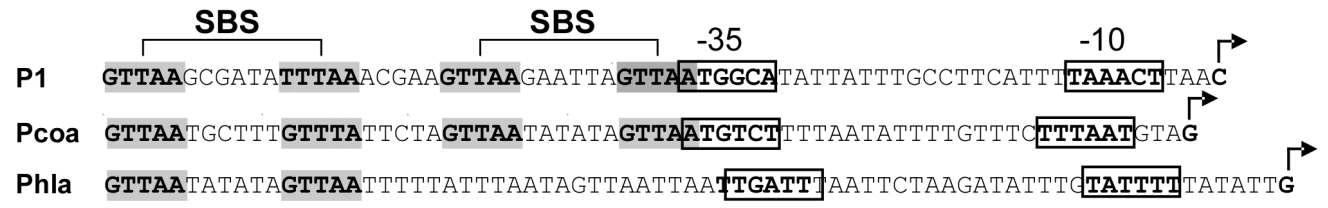

Figure 1. The sae operon. (A) Organization of the sae operon. Two angled arrows represent the P1 and P3 promoters, respectively. Two vertical lines in the P1 promoter region indicate the SaeR binding sequences (SBSs). The nucleotide sequence of the P3 promoter is shown under saeQ, where $\mathrm{N}_{17}=17$ nucleotides. Four transcripts (T1-T4) are indicated by arrows; (B) DNA sequences of select sae target promoters. The SBSs are shown in gray. Transcription start sites are indicated by angled arrows. The promoter sequences are shown in boxes. Pcoa, the promoter of coagulase (coa); Phla, the promoter of $\alpha$-hemolysin (hla).

\subsubsection{P3 Promoter (saeP3)}

The P3 promoter is located inside saeQ and transcribes only saeR and saeS (i.e., the T3 transcript in Figure 1A) [15,18]. The P3 promoter is weaker than P1 and constitutive [18,20]. The transcription of saeRS from P3 is sufficient for activation of the Sae target genes. In fact, deletion of the sae sequence upstream of P3 did not significantly affect exoprotein production [18]. Therefore, the constitutive P3 promoter provides the basal levels of SaeS and SaeR for sensing and responding to cognate signals.

\subsubsection{P1 Promoter (saeP1)}

The P1 promoter resides in the front of the very first gene saeP and can transcribe all four genes (Figure 1A). As compared with P3, P1 is much stronger and, due to two SBSs, it is autoinduced by the SaeRS TCS (Figure 1B) [15,19]. From the P1 promoter, T1 transcript is produced and further processed into T2 and T4 (Figure 1A). When P1 is induced, due to the increased transcripts, the SaeRS protein levels also increase. However, the increase of SaeRS is not expected to further increase the activity of the SaeRS TCS because (1) overexpression of saeRS does not alter the expression pattern of the Sae-regulon (coa, eap, and hla) [21], and (2) the production of SaePQ from P1 reduces the overall Sae activity by inducing SaeS's phosphatase activity (see SaeP \& SaeQ below) [18]. 


\subsection{SaeS}

SaeS is composed of 351 aa where His131 is the phosphorylation site [13]. As a sensor histidine kinase, its kinase activity determines the level of SaeR-P, the effector molecule of the SaeRS TCS. Although, as a bifunctional histidine kinase, SaeS is supposed to have both kinase and phosphatase activities, purified MBP (maltose binding protein)-SaeS fusion protein shows no significant phosphatase activity [22]. On the other hand, SaeS has a low but significant basal kinase activity, which allows the expression of hla without induction (see Section 4 for detailed discussion) [21,23]. SaeS consists of a transmembrane domain, a HAMP domain, and a kinase domain (Figure 2A). Although the exact boundary of transmembrane domain has not been experimentally determined, SaeS is predicted to have a nine aa-long linker peptide between two transmembrane helices [23,24]. Since the linker peptide is too small to serve as a ligand binding domain, SaeS is classified as a member of intramembrane-sensing HKs (IM-HK) $[25,26]$.

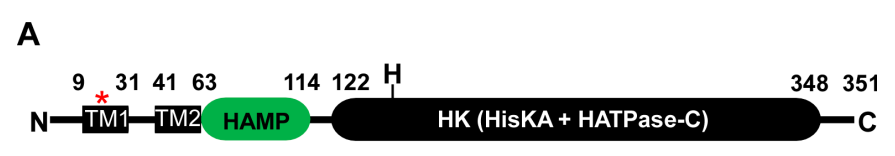

B

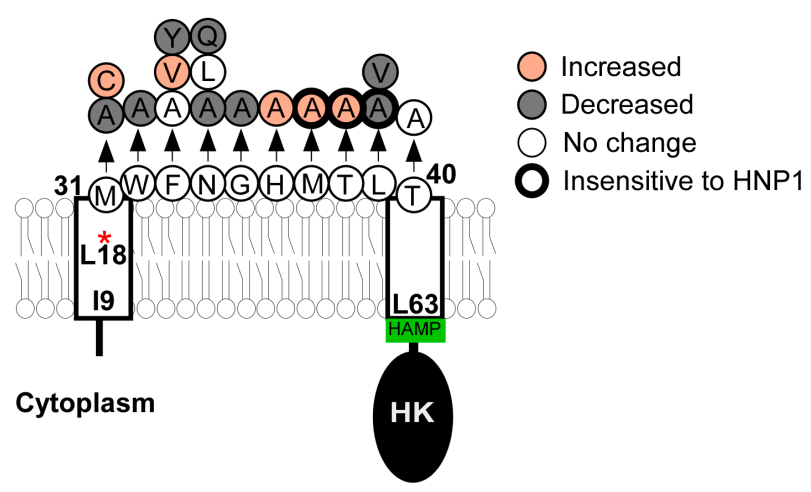

Figure 2. The SaeS protein. (A) The domain structure of SaeS. The numbers represent the boundary amino acids. The red star indicates the L18P mutation of SaeS in the strain Newman. N,N-terminus; H, His 131; C,C-terminus; TM, transmembrane helix; HK, histidine kinase; (B) A summary of mutations in the transmembrane domain of SaeS. Increased, Increased basal kinase activity; Decreased, Decreased basal kinase activity; No change, No effect on the basal kinase activity; Insensitive to HNP1, Kinase activity does not respond to HNP1. The positions of amino acids are all predictions.

\subsubsection{Transmembrane Domain}

In SaeS, the transmembrane domain of SaeS is necessary and sufficient to respond to the activation signal human neutrophil peptide 1 (HNP1) [23]. Although SaeS of Staphylococcus epidermidis does not respond to HNP1, when the transmembrane domain was swapped with that of S. aureus, the hybrid SaeS did [23]. In addition, the transmembrane domain affects the basal kinase activity of SaeS. For example, in the strain Newman, the L18P mutation in the first transmembrane helix dramatically increases the kinase activity of SaeS [24,27]. Alanine substitutions of the linker peptide also altered the kinase activity of SaeS and/or the response to HNP1 (Figure 2B) [23,28]. Two hypotheses were proposed to explain how the transmembrane domain affects the kinase activity of SaeS. Flack et al. [28] found that the amino acids Met, Trp, and Phe (aa 31-33, MWF in Figure 2B) are conserved in all SaeS orthologues in staphylococci, and that the alanine substitutions of those amino acids, in particular, the Met31 residue, greatly reduced $\alpha$-hemolysin (hla) promoter activity and hemolytic activity of culture supernatant. Based on those results, Flack et al. proposed that the conserved amino acids are critical for SaeS kinase activity. On the other hand, Liu et al. [23] found that 
the effects of amino acid substitutions in the linker peptide vary depending on the substituting amino acids. For example, although the M31A substitution decreased the kinase activity of SaeS, the M31C substitution increased it. Similarly, the F33Y substitution decreased the kinase activity of SaeS whereas the F33V substitution increased it (Figure 2B). Based on these results, Liu et al. proposed that the overall conformation of the transmembrane domain, not MWF residues, is critical for the SaeS's kinase activity (a tripwire model) [23]. This model predicts that any molecules altering the conformation of the transmembrane domain can serve as a signal for SaeS.

\subsubsection{Growth-Phase Dependent Activation}

The transcription of the sae operon from the P1 promoter is affected by growth phase and is maximal in the post-exponential growth phase $[15,19]$. The transcription of the Sae target genes such as $f n b A$, coa, and hla showed growth-dependency even in the mutant of Agr, the staphylococcal quorum sensing system, indicating that the growth-phase-dependent Sae activation is independent of Agr [29,30]. The molecular mechanism underlying the results is unknown. However, since the kinase activity of SaeS determines the extent of the Sae target gene activation, these results suggest that the kinase activity of SaeS increases in a growth dependent but Agr-independent manner.

\subsection{SaeS Variants}

SaeS shows polymorphisms, and three SaeS variants are known: SaeS ${ }^{\mathrm{P}}$, SaeS ${ }^{\mathrm{SK}}$, and SaeS ${ }^{\mathrm{SKT}}$.

\subsubsection{SaeS $^{\mathrm{P}}($ SaeS L18P)}

This SaeS variant has a L18P substitution mutation (T53C mutation in saeS) in the first transmembrane helix (Figure 2). This variant protein was originally identified in the strain Newman [19,24], but is also found in other strains too (e.g., LysK 1 2010, Lyso 1 2010, 1101-2 2010, 1801-1 2010) [117]. Due to the substitution mutation, the kinase activity of SaeS ${ }^{P}$ is highly increased. For example, the cell lysate of the strain USA300, which produces wild type SaeS (SaeS $\left.{ }^{\mathrm{L}}\right)$, did not visibly phosphorylate SaeR; however, the Newman cell lysate did [31]. Along with the heightened kinase activity, signal response was also altered in SaeS ${ }^{P}$. When treated with 0.006\% SDS (sodium dodecyl sulfate), the kinase activity of SaeS ${ }^{\mathrm{P}}$ was further increased whereas that of wild type SaeS was inhibited [27]. Since other detergents such as Triton X-100 and Tween 20 did not affect the kinase activity of SaeS $^{\mathrm{P}}$ [27], SDS seems to be a specific signal for SaeS ${ }^{\mathrm{P}}$. Due to the high kinase activity of $\mathrm{SaeS}^{\mathrm{P}}$, the auxiliary proteins SaeP and SaeQ are constantly expressed in the strain Newman. However, those auxiliary proteins are not involved in the SDS-mediated activation of SaeS $S^{\mathrm{P}}$ [32]. Co-expression of SaeS ${ }^{L}$ suppressed the target gene expression by SaeS ${ }^{P}[21,24]$, indicating that SaeS ${ }^{P}$ can have high kinase activity only in a form of homodimer.

Another unique trait of $\mathrm{SaeS}^{\mathrm{P}}$ is its instability in the absence of SaeQ. Without SaeQ, almost no SaeS $^{\mathrm{P}}$ was detected [18]. This result indicates that $\mathrm{SaeS}^{\mathrm{P}}$ is subject to proteolytic degradation in the membrane, from which SaeQ protects $\mathrm{SaeS}^{\mathrm{P}}$.

\subsubsection{SaeS $S^{S K}$ and SaeS $^{\text {SKT }}$}

SaeS $^{\text {SK }}$ has two substitution mutations (N227S and E268K) and is found in the strains MW2, Mu50 and USA600 [33]. Those substitutions, however, do not seem to alter the enzymatic activity of SaeS because they do not affect the production of nuclease, a member of Sae-regulon [33]. Recently, SaeS ${ }^{\text {SKT }}$, a SaeS ${ }^{S K}$ variant with one more amino acid substitution at the last position (S351T) was reported in ST30 and ST36 lineages of S. aureus [34]. Interestingly, unlike the wild type Sae system, whose activity increases in a growth phase-dependent manner and is maximal at the post-exponential growth phase $[15,19]$, the activity of the Sae system with SaeS ${ }^{\text {SKT }}$ appeared to be highest in the exponential growth phase and reduced in the stationary growth phase [34]. The molecular basis of the altered activation pattern remains to be elucidated. 


\subsection{SaeR}

SaeR is an OmpR family response regulator composed of 228 amino acids ( $\mathrm{pI}=$ 5.2.). At its N-terminus, SaeR contains the receiver domain where Asp51 is the phosphorylation site. Phosphorylation at Asp51 is essential for SaeR to bind its target DNA [31]. Indeed, the D51N substitution in SaeR abolished the expression of coa and hla [21]. At its C-terminus, SaeR contains the DNA binding domain $\left(S_{a e R}{ }^{D B}\right)$. Unlike SaeR, which does not bind DNA without phosphorylation, SaeR ${ }^{\mathrm{DB}}$ does bind DNA, demonstrating that, in SaeR, the unphosphorylated receiver domain prevents the DNA binding of SaeR ${ }^{\mathrm{DB}}$ [31]. The crystal structures of SaeR ${ }^{\mathrm{DB}}$ (aa 125-228 or 128-228) revealed that SaeR ${ }^{\mathrm{DB}}$ exists as a monomer with a winged helix-turn-helix module [35,36]. From the structural studies, K174, H198, R199, R201, W218 were predicted and confirmed to be critical for DNA binding and transcription activation of target genes [35].

SaeR Binding Sequence (SBS)

The perfect binding sequence of SaeR-P is GTTAAN ${ }_{6}$ GTTAA, where $\mathrm{N}=$ any nucleotide with preference to $A / T[31,37]$ (Table 1 ). Of the GTTAA sequence, $G$ is not absolutely required for the SaeR-mediated transcription activation while TTAA appears to be. For instance, when $\mathrm{G}$ was mutated to $\mathrm{C}$ in P1, the mutant P1 still showed significant promoter activity ( $20 \%$ of wild type); however, when similar single substitution mutations were made in the TTAA sequence, the resulting mutant P1 promoters showed almost no promoter activity [31]. Indeed, the consensus SaeR binding sequence indicates that the TTAA sequence plays a major role in SaeR-mediated transcription activation (Figure 3).

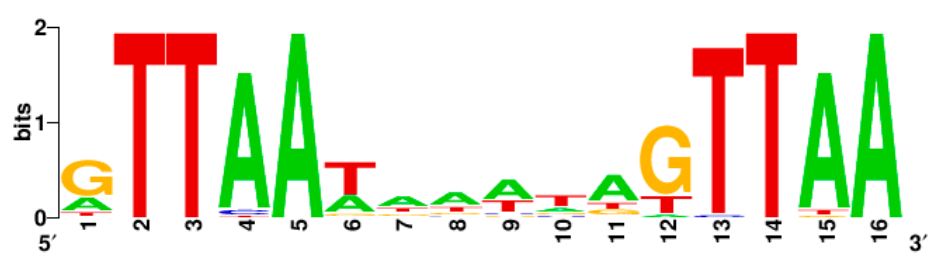

Figure 3. The consensus sequence of the SaeR binding sequence. It was generated by WebLogo (http://weblogo.berkeley.edu/logo.cgi) using the SaeR binding sequences in Table 1.

\subsection{SaeP and SaeQ}

saeP and saeQ are auxiliary genes upstream of saeRS [15]. saeP encodes a lipoprotein of 146 aa $(\mathrm{pI}=9.87)$ while sae $Q$ encodes a membrane protein of 157 aa $(\mathrm{pI}=9.76)$ with four predicted transmembrane helices (Figure 4) [19,22]. The N-terminal sequence of SaeP is known to show one or more polymorphisms [19]. Neither SaeP nor SaeQ shows significant homology to proteins of known functions. SaePQ are dispensable for the activation of the Sae system $[18,21]$, however, they are required to induce SaeS's phosphatase activity by forming a SaePQS ternary complex (Figure 4) [22]. Interestingly, the phosphatase activity of the cytoplasmic domain of SaeS (SaeSc), which cannot interact with SaeP, is also enhanced by SaePQ in vitro [22]. Therefore, it is likely that the SaeQ-SaeS interaction in the cytoplasm is directly responsible for the activation of SaeS's phosphatase activity. The interacting parts of SaeP, SaeQ and SaeS, and the molecular mechanism of the activation are not yet known. 


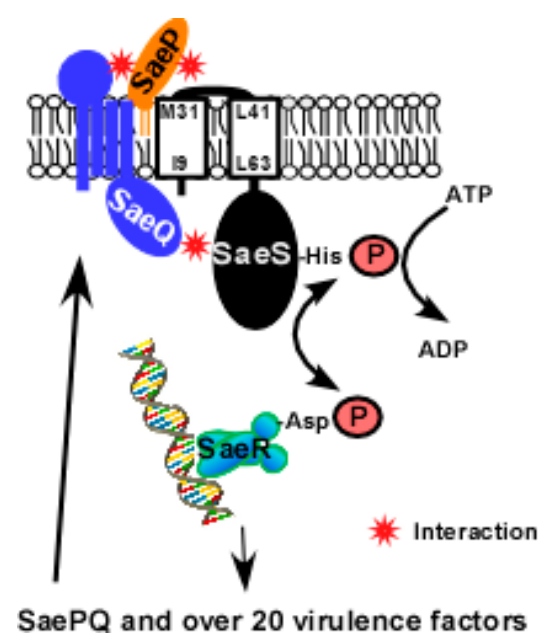

Figure 4. A model for SaePQS interaction. Upon exposure to the inducing signal(s), SaeS autophosphorylates the conserved His residue with ATP; then the phosphoryl group is transferred to the conserved Asp residue of SaeR. The phosphorylated SaeR binds to its binding sequence and activates transcription from target promoters including the saeP1 promoter. From saeP1, SaeP and SaeQ are produced and bind to SaeS in the membrane. As a lipoprotein, SaeP is expected to interact with the extracellular linker peptide of SaeS. On the other hand, SaeQ is thought to interact with the cytoplasmic domain of SaeS [22]. The interacting parts of SaePQS are based on predictions.

\section{Signals}

\subsection{Activation Signals}

\subsubsection{Human Neutrophil Peptide 1, 2, and 3 (HNP1-3)}

Human neutrophil peptide 1, 2, and 3 (HNP1-3) are antimicrobial peptides produced by human neutrophils, constituting $30 \%$ to $50 \%$ of the total protein in azurophilic granules, the primary contributor to the killing and degradation of microorganisms in phagolysosomes [38]. HNP1-3 activate the Sae system at subinhibitory concentrations $(0.5-20 \mu \mathrm{g} / \mathrm{mL}, \mathrm{MIC}=200 \mu \mathrm{g} / \mathrm{mL})$ [14]. The activation is specific because other antimicrobial peptides such as LL37, daptomycin, and vancomycin show no effect on the Sae system [14]. Intriguingly, the HNP effect is strain-specific. Although HNP activates the Sae system in the strains USMS-1, MW2, N315, USA300, MRSA252, and MSSA476, it does not in the strains ISP479R, COL, and Newman [14]. The strain-specific effect of HNP has not yet been explained. It is also unknown whether HNPs directly bind to SaeS or not. Since HNPs are produced by human neutrophils, it is not surprising that human neutrophils also activate the Sae system $[39,40]$. Intriguingly, the Sae system is also activated by murine neutrophils, which do not produce alpha-defensins like HNP1-3 [40-42], indicating that other Sae-activating molecules are present in murine neutrophils.

\subsubsection{Calprotectin}

Calprotectin is a member of the EF-hand calcium binding protein family and is composed of the heterodimeric complex of S100A8 / A9 (also called Mrp8/14) [43]. It is abundantly expressed in neutrophils, constituting approximately $50 \%$ of neutrophil cytoplasmic proteins, and its concentration in tissue abscesses is over $1 \mathrm{mg} / \mathrm{mL}[44,45]$. In abscesses, calprotectin suppresses staphylococcal growth by sequestering the nutrient metal ions $\mathrm{Zn}$ and $\mathrm{Mn}[45,46]$. The $\mathrm{Zn}$-bound form of calprotectin is known to protect the Sae system from inhibition by $\mathrm{Zn}$ and Fe [42], although the mechanism is still unknown. 


\subsubsection{Other Activation Signals}

Inhibitory concentrations of hydrogen peroxide and subinhibitory concentration of beta-lactam antibiotics were reported to activate the Sae system $[14,47,48]$. However, in our hands, beta-lactam antibiotics such as oxacillin does not activate the SaeRS TCS but rather reduced the sae transcription from the P1 promoter (Appendix Figure A1). Therefore, the effect of beta-lactams is strain-specific, and it is unlikely that beta-lactam antibiotics are signal molecules for the Sae system.

\subsection{Inhibitory Signals}

\subsubsection{Silkworm Apolipophorin Protein}

This protein is known to reduce the transcription of the hemolysin genes (hla and hlb), saeS, and saeQ [49]. It binds to lipoteichoic acid (LTA), and the LTA complexed with the protein inhibits the kinase activity of SaeS by interacting with transmembrane domain of SaeS, in particular, the linker peptide region [50]. When SaeS was mutated in the transmembrane helices (i.e., I9Q and I9Q/L63Q) or in the linker peptide (i.e., $\Delta 34-36, \Delta 35-37, \Delta 34-37$ ), the kinase activities of the resulting mutant SaeS proteins were either non-responsive to (I9Q) or activated by the apolipophorin protein [50].

\subsubsection{Acidic $\mathrm{pH}$ and $1 \mathrm{M} \mathrm{NaCl}$}

At $\mathrm{pH} 5.5$ or in the presence of $1 \mathrm{M} \mathrm{NaCl}$, the P1 promoter activity was repressed [14,51] although it was not inhibited in the Newman strain background (i.e., SaeS ${ }^{P}$ variant) [24].

\subsubsection{Other Potential Sae Inhibitory Molecules}

The human skin fatty acid cis-6-hexadecenoic acid was reported to repress the Sae system, although the mechanism is not known [52]. 18ß-glycyrrhetinic acid, a component of the licorice root Glycyrrhiza spp., was also shown to inhibit the transcription of saeR and hla, raising the possibility that it might specifically repress the Sae system. Schmitt et al. showed that haemin reduces the transcription of $h l b$ and $h \lg A$ in a Sae-dependent manner [53] while Baker et al. showed that $\mathrm{Cu}$ represses the Sae system [54]. Indeed, in an in vitro enzyme assay, $\mathrm{Cu}$, along with $\mathrm{Zn}$ and $\mathrm{Fe}$, was shown to inhibit the kinase activity of SaeS [42], possibly competing with Mg in SaeS. Finally, the following molecules have been reported to inhibit the expression of the sae-operon or some members of Sae-regulon and have a potential to be a Sae inhibitor: florfenicol [55], corilagin [56], licochalcone A [57], thymol [57], the enoyl-acyl carrier protein reductase inhibitor AFN-1252 [58], cerulenin [59], subinhibitory concentration of linezolid [60], Manuka honey [61], and flavone [62].

\section{The Sae Target Genes}

The direct Sae target genes harboring SBS in their promoter region are listed in Table 1. Two different classes of the Sae target promoters were identified. The class I (or low affinity) targets (e.g., coa, fnbA, eap, sbi, efb, fib, and saeP) are highly expressed in strain Newman, which has SaeS ${ }^{\mathrm{P}}$, while the class II (or high affinity) targets ( $h l a$ and $h l b$ ) are insensitive to the SaeS polymorphism [21,23]. The class I target promoters appear to have a low affinity for SaeR-P, and their transcription requires relatively high levels of SaeR-P. On the other hand, the class II target promoters seem to have a high affinity to SaeR-P, and the basal level of SaeR phosphorylation is sufficient for their transcription [21]. Further study on the coa, saeP1, and hla promoters has shed light on the molecular basis of their different SaeR-P requirements. First, the class I targets such as coa and saeP1 promoters have two SBSs, while the class II target hla promoter has only one (Figure 1B). Therefore, regardless of their binding affinities to SaeR-P, the transcription of the class I targets will require twice as much SaeR-P as that for the class II targets. Second, in the absence of SaeR-P, the class I target promoters (i.e., coa and saeP1) do not bind to RNA polymerase whereas the class II target promoter (i.e., hla) does [63], indicating that, 
even in the absence of SaeR-P, the hla promoter can be occupied by RNA polymerase and be ready for transcription.

Table 1. Direct targets of the SaeRS TCS.

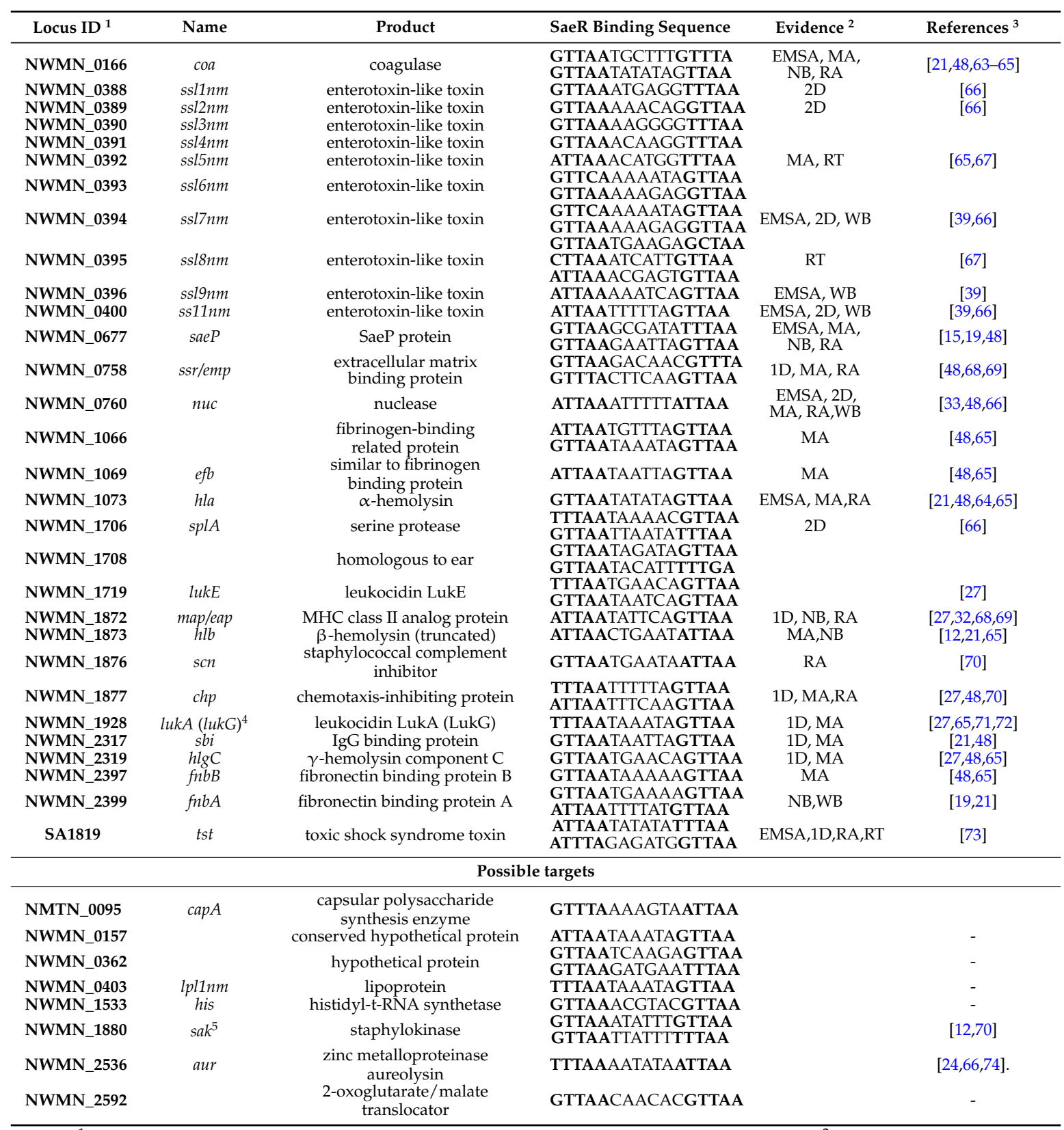

${ }^{1}$ Based on the genome of the strain Newman except for tst, which is from the strain N315; ${ }^{2}$ 1D, SDS-PAGE; 2D, 2D gel electrophoresis; EMSA, Electrophoretic mobility shift assay; MA, Microarray analysis; NB, Northern blot; RA, Reporter assay; RT, RT-PCR; WB, Western blot; ${ }^{3}$ Only select references are shown; ${ }^{4}$ Although NWMN_1928 is annotated as $l u k S$ in Newman genome sequence, it was renamed to $l u k A(l u k G)$ [71,72]; ${ }^{5}$ Although sak contains a perfect SBS, according to the references, the transcription of sak is not significantly affected by sae mutation.

The organization of SBSs varies among the Sae target promoters (Figure 5). Such variations along with promoter strength are expected to affect the sensitivity of those promoters to SaeR-P and to shape the overall regulation patterns. Of the promoters, six have 1.5 SBS (i.e., three half binding sites). Since it is unlikely that all three half-binding sites are occupied by SaeR-P simultaneously, one of the half-binding sites at the boundary might be non-functional, leaving only one SBS. In the promoters of 
ssl8nm, fnbA and $f n b B$, SBSs are placed in an opposite orientation. It remains to be determined how SaeR-P activates transcription from those promoters.

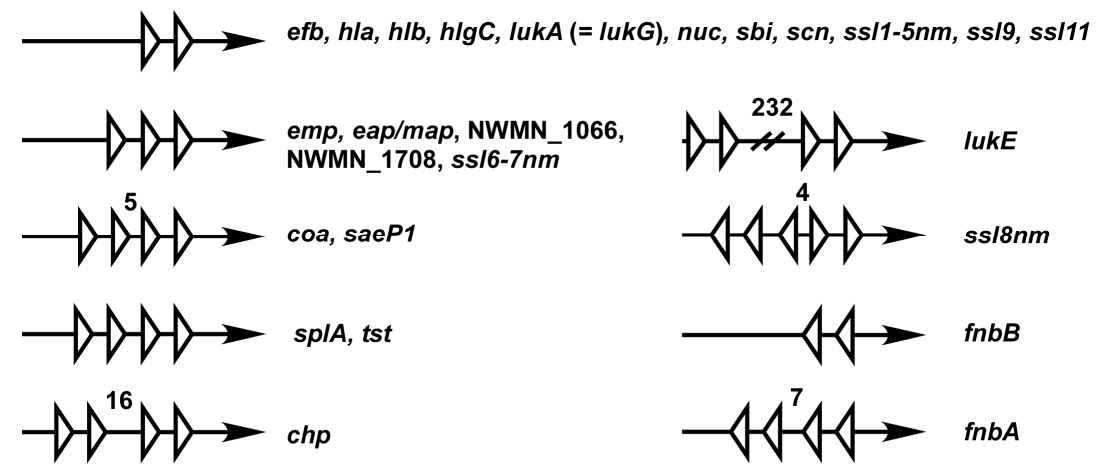

Figure 5. Organization of SBSs in the sae target gene promoters. Each white triangle represents a half of the SaeR binding sequence. Arrows represent promoter region pointing the direction of transcription. Unless stated otherwise, the distance between each half binding sequence is $6 \mathrm{bp}$. Numbers are base pairs of the gap between the half-binding sites.

Although the Sae system mostly activates target gene expression, some genes are known to be downregulated by the system. In the strain Newman, a sae mutant expressed more capsular antigen than the wild type did $[19,75]$. Indeed, the cap promoter activity was also higher in the sae mutant [19]. However, since the putative SBS in the cap promoter is rather poorly conserved (Table 1), it is not clear whether or not the SaeR-P directly binds and represses the cap promoter. The Sae system is also known to repress the expression of aureolysin (Aur), a zinc metalloproteinase [24,66,74]. In the sae mutant, the increased production of Aur contributes to the lower level of exoproteins in the culture supernatant [74]. However, the putative SBS in aur is also poorly conserved (Table 1), and the transcription of the aur gene was not significantly affected in the saeS mutant [66]. Therefore, it is possible that the Sae-mediated repression of aur is indirect.

\section{Interaction with Other Regulators}

As shown in Table 1, the Sae system does not directly control the transcription of other global regulatory genes such as $a g r, \operatorname{sig} B, \operatorname{sar} A$, or $\operatorname{rot}[14,20,64,66,76]$. However, the transcription of the sae-operon is known to be affected by other regulatory systems.

\subsection{Agr}

Agr is the staphylococcal quorum sensing two-component system where AgrC and AgrA are the sensor histidine kinase and the response regulator, respectively [77]. AgrC is activated by autoinducing peptide, which is encoded by $\operatorname{agrD}$, and phosphorylates AgrA. The phosphorylated AgrA (AgrA-P) binds to the $\mathrm{P} 2$ and $\mathrm{P} 3$ promoters of the agr operon and activates the transcription of agrBDCA and RNAIII, the major effector molecule of the Agr system. Along with the agrP2 and P3 promoters, the psm (phenol soluble modulin) promoters are known to be a direct target of AgrA [78].

Based on the effect of an agr mutation on the transcription of the sae operon, the Sae system has been suggested to be downstream of Agr in the exoprotein production pathway [15]. For example, agr mutation reduced both the saeP1 promoter activity and the Sae mRNA level [13-15,79]. In the strain ISP479, a derivative of the strain 8325-4, an agr mutation greatly reduced the saeP3 promoter function in the $1.15 \mathrm{~kb}$ fragment upstream of saeR [80]. Novick et al. also showed that RNAIII was required for sae transcription from saeP1 [15]. However, other experimental results also suggest that Agr and Sae are independent of one another. First, the sae operon contains neither AgrA nor RNAIII binding sequences. Therefore, the effect of the agr mutations on the sae expression must be indirect. Second, some target genes are regulated by Agr and Sae in an opposite manner. For example, coa and fnb $A$ are 
repressed by Agr but activated by Sae $[19,64,81,82]$. The cap gene is activated by Agr but repressed by Sae $[19,83,84]$. In the case of TSST-1, the toxin responsible for toxic shock syndrome [85], both Agr and Sae are positive regulators [73]. However, the deletion of $a g r$ did not abolish the production of TSST-1 whereas sae-deletion did [73]. Third, several in vivo model experiments showed that Sae is critical for toxin production whereas Agr is dispensable. For instance, during device-related infection in guinea pigs, Sae was required for the expression of hla while Agr was not [76], despite the fact that, in the in vitro condition, Agr positively regulates the hla expression with RNAIII at a post-transcription level [86]. During murine skin infection of the USA300 strain, the Sae target genes such as $h \lg A, h \lg B$, $h \lg C$, and $l u k A$ were highly expressed in the agr mutant but abolished in the sae mutant [40]. In an infective endocarditis model, the hla transcript level was significantly reduced in the sae mutant but not in $\operatorname{agr}$, sar $A$, or $\operatorname{agr} / \mathrm{sar} A$ mutants [4]. Steinhuber et al. showed that, under elevated $\mathrm{CO}_{2}$, Sae is critical for the hemolytic phenotype but Agr is not [19]. These results cannot be explained by the direct regulation of Sae by Agr. Finally, as stated in Section 2.1, the target gene expression is not affected by the expression level of the sae operon [21]. Therefore, even though Agr might affect the sae transcription from P1, it would not affect the overall Sae activity (i.e., the expression level of the Sae targets). It should be noted that some results from early studies are questionable. For example, in the 2003 study by Giraudo et al. [80], despite the fact that agr mutation abolished the promoter activity of saeP3 at $\mathrm{OD}_{600}=4$, no significant changes were observed in the transcript profile analyzed by Northern blot. Moreover, in most studies, the effect of agr mutation on the sae expression was not confirmed by a complementation test $[13,14,79]$. Recently, Baroja et al. showed that, in the strain MN8, the deletion of agr did not affect the transcription of saeR [73], further confirming the independence of Agr and Sae.

\subsection{WalRK}

In S. aureus, the WalRK TCS is essential for cell viability and plays a key role in cell wall metabolism $[87,88]$. When a constitutively active form of the response regulator WalR (i.e., WalR D55E) was produced, most members of the Sae regulon including the sae operon were up-regulated, and the up-regulation was abolished by the deletion of saeRS [89]. This study strongly suggests that WalRK can positively affect the SaeRS TCS, although the molecular mechanism is unknown.

\section{3. $\operatorname{Sig} B$}

The alternative sigma factor $\sigma^{\mathrm{B}}$ is a global regulator controlling the expression of genes in response to various stresses such as heat, infection, oxidative molecules and antibiotics [90-92]. $\sigma^{B}$ was reported to activate the expression of $c o a[93,94]$, which has the $\sigma^{\mathrm{B}}$ promoter sequence [95]. However, $\sigma^{\mathrm{B}}$ is also known to downregulate the transcription of the sae operon from the P1 promoter and other Sae target genes such as hla, hlgABC, nuc, and splABCDEF [93]. Since sigma factors bring RNA polymerase to promoter sequences, the downregulation of the Sae-regulon by $\sigma^{\mathrm{B}}$ must be indirect, possibly mediated by regulatory proteins or small non-coding RNAs that are positively regulated by $\sigma^{\mathrm{B}}$ [96]. Indeed, in their study on the role of Sae and $\sigma^{\mathrm{B}}$ in virulence gene expression during device-related infection, Goerke et al. found no evidence of cross talk between the two regulators [97], indicating that Sae and $\sigma^{\mathrm{B}}$ are independent regulatory systems.

\subsection{Fur}

As a global regulator of iron homeostasis, Fur controls the expression of genes required for iron uptake functions in response to iron-availability [98-100]. In S. aureus, Fur also controls the genes required for biofilm formation and anti-oxidative stress response [101-103]. Addition of exogenous iron in the media significantly decreased the saeRS transcription from the constitutive P3 promoter and marginally reduced the transcription from the inducible P1 promoter [79]. In addition, the transcription of sae and many of the Sae-regulated genes was reduced in the fur mutant [79], implying that Fur may act as a positive regulator of the SaeRS TCS. However, the sae operon does not have Fur-binding sites, 
and Cho et al. has reported that saeP1 promoter activity was not affected by Fur [42]. Therefore, any Fur-mediated regulation of the Sae system is questionable.

\subsection{Other Regulators}

Rot (repressor of toxins) is a member of the SarA protein family and represses the expression of hla $[20,104]$. Rot is also known to reduce the promoter activity of the saeP1 promoter by an unknown mechanism [20]. Based on the result, Rot was suggested to repress the hla expression via Sae [20]. However, since the P1 promoter has no role in regulation of the transcription of Sae targets [18], it is unlikely that the hla repression by Rot was mediated by Sae.

Recently, it has been reported that mutation of genes encoding fatty acid kinase (fak $A$ and fakB1/fakB2) significantly decreased $\alpha$-hemolysin production and lowered the expression of Sae target genes [105], raising the possibility that the Fak system positively affects the SaeRS TCS. It was suggested that, similar to acetyl phosphate in Gram-negative bacteria [106], the acyl- $\mathrm{PO}_{4}$ form of FakB might serve as a phosphoryl group donor for SaeR [105].

\section{The Role of Sae in the Virulence of S. aureus}

\subsection{Biofilm Formation}

S. aureus forms a biofilm, which enables the bacterium to resist antimicrobial therapy and host defenses [107]. A well-defined mechanism of biofilm formation is the production of the icaADBC-encoded polysaccharide intercellular adhesin (PIA, also known as polymeric N-acetyl-glucosamine, PNAG) [108-110]. S. aureus also forms a biofilm in a PIA/PNAG-independent manner, utilizing diverse molecules such as surface proteins, secreted proteins, and released extracellular DNA (eDNA) [111]. Staphylococcal biofilm formation is affected by growth conditions (e.g., $\mathrm{NaCl}$, glucose, human plasma etc.) [112,113] and is controlled by multiple global regulators such as SarA, Agr, SigB, and Sae. [111,113-117]. The Sae-regulon includes both the factors promoting biofilm formation (i.e., Coa, Emp, Eap, FnBPA, FnBPB, Hla, Hlb) [69,113,118-121] and biofilm dispersal factors (nuclease and proteases) (Table 1). Therefore, it is possible that, depending on growth conditions and strain backgrounds, the Sae system could affect biofilm formation either positively or negatively. For example, Cue et al. showed that the high kinase activity of SaeS ${ }^{\mathrm{P}}$ is responsible for the poor biofilm formation of the strain Newman [117]. Indeed, either deletion of the sae operon or replacement of $\mathrm{SaeS}^{\mathrm{P}}$ with SaeS ${ }^{\mathrm{L}}$ greatly enhanced the biofilm formation. The study also indicated that the strain Newman secretes a heat-stable protein that inhibits biofilm formation. However, the nature of the biofilm inhibitor has not been determined [117]. In iron (Fe)-free cell culture medium (RPMI-1640) containing plasma, however, the Sae system was required for biofilm formation, where coagulase (Coa)-catalyzed conversion of fibrinogen into fibrin played an essential role [113]. Intriguingly, in tryptic soy broth (TSB), the Sae system was dispensable for biofilm formation [113]. Johnson et al. reported that an Fe-restricted growth condition induces biofilm formation by the strain Newman via the expression of the Sae-regulated proteins Emp and Eap (Table 1) [69]. Since Fe represses the Sae system [42], it is likely that the low iron-condition increased the overall Sae-activity, leading to the enhanced expression of Emp and Eap. Baker et al. also reported that a high level of $\mathrm{Cu}$ repressed the biofilm formation of the strain Newman in CRPMI medium, while Mn, Mg, and Ca did not [54]. These results are consistent with the report that the kinase activity of SaeS is inhibited by $\mathrm{Cu}$, but not by $\mathrm{Mn}, \mathrm{Mg}$, or Ca [42]. In S. aureus, SarA plays a positive role in biofilm formation, and sar A mutation generally reduces staphylococcal biofilm formation [122,123]. However, sar $A$ mutation does not affect biofilm formation in the strain Newman [122,124]. Intriguingly, either deletion of the sae operon or the replacement of SaeS ${ }^{\mathrm{P}}$ with the wild type SaeS restored the positive role of SarA [124], showing that the high kinase activity of $\mathrm{SaeS}^{\mathrm{P}}$ is responsible for the lack of biofilm phenotype of the sarA mutation in the strain Newman. 


\subsection{Invasion of Host}

SCIN (staphylococcal complement inhibitor) and CHIPS (chemotaxis inhibitory protein of staphylococci) are efficient inhibitors of neutrophil chemotaxis, phagocytosis and killing [70], and the expression of both molecules are positively regulated by the SaeRS TCS (Table 1). Neutrophils, the key effectors of the host innate immune response, can release DNA in the form of neutrophil extracellular traps (NETs), which capture and eliminate microbes [125]. S. aureus can destroy NETs by producing nuclease, a member of the Sae-regulon (Table 1) [126]. Furthermore, S. aureus is known to survive within phagocytes and many types of cells, and the Sae-regulated toxins (LukAB and LukED) can damage phagocytes such as macrophages and neutrophils, helping $S$. aureus escape from the killing by the phagocytes [127]. The SaeRS TCS is required for adhering to and invading lung epithelial cells (A549) by regulating a novel hypothetical protein (SA1000) and efb [65]. $\alpha$-hemolysin (Hla) can cause a significant damage to the plasma membrane of the human CD14 ${ }^{+}$monocyte [128]. The SaeRS TCS has been reported to induce the production of localized and systemic pro-inflammatory cytokines, including tumor necrosis factor alpha (TNF- $\alpha$ ), Interferon gamma (IFN- $\gamma$ ), Interleukin (IL) 6 and IL-2 [40,42,129].

Considering the protective roles of the SaeRS TCS described above, it is not surprising that the SaeRS TCS is required for disease progression in several animal models of infection including silkworm and nematode killing [130,131], murine survival and skin infection [132], infective endocarditis [4], necrotizing pneumonia and skin infection [133], osteomyelitis [74], and sepsis [134]. The SaeRS TCS was even needed for staphylococcal gastrointestinal dissemination and transmission following bacteremia [135].

\section{Conclusions}

In S. aureus, the SaeRS TCS plays a key role in production of over 20 virulence factors (Table 1), and pathogenesis of the bacterium. None of those virulence genes are found in the closely related S. epidermidis, which also has the SaeRS TCS $[136,137]$. Therefore, S. aureus seems to have evolved its virulence capacity by acquiring those virulence genes and placing them under the control of the SaeRS TCS. Despite intense research on the Sae system over the past two decades, we still do not know how cognate Sae signals such as HNPs are sensed by SaeS. Do HNPs directly bind SaeS? Or do they activate SaeS via a hitherto-unidentified receptor molecule? On top of that, HNPs do not activate the SaeRS TCS in certain strain backgrounds, and the reason is completely unknown. As discussed in Section 3, the SaeRS TCS is affected by diverse molecules such as HNPs, LTA, calprotectin, and metal ions. This might be due to the fact that the entire transmembrane domain of SaeS is either buried in the membrane (TMs) or in close contact (the linker peptide) with molecules in the membrane. Since the kinase activity of SaeS appears to respond sensitively to the overall conformation of the transmembrane domain, any molecules, either exogenous or endogenous, that alter the conformation of the SaeS transmembrane domain are expected to serve as a legitimate signal for the SaeRS TCS. Certainly, more biochemical and mechanistic studies are needed to define the mechanism by which the enzymatic activity of SaeS is modulated by those signals. Finally, there is no direct evidence yet that the SaeRS TCS is directly regulated by other regulatory systems. In particular, the SaeRS TCS and the Agr quorum sensing system are likely independent of one another.

Acknowledgments: This study was, in part, supported by NIH (AI121664) to TB and the National Natural Science Foundation of China (grant 81501803) and the Shanghai Committee of Science and Technology, China (grant 14ZR1424600) to QL.

Author Contributions: Q.L., W.Y., and T.B. equally contributed to the conception, design, and writing of this manuscript.

Conflicts of Interest: The authors declare no conflict of interest. The funding sponsors had no role in the design of the study, in the collection, analyses, or interpretation of data, in the writing of the manuscript, and in the decision to publish the results. 


\section{Abbreviations}

The following abbreviations are used in this manuscript:

TCS Two-component system

SBS SaeR binding sequence

HK Histidine kinase

$\mathrm{SaeR}^{\mathrm{DB}} \quad$ The DNA binding domain of SaeR

LTA Lipoteichoic acid

\section{Appendix}

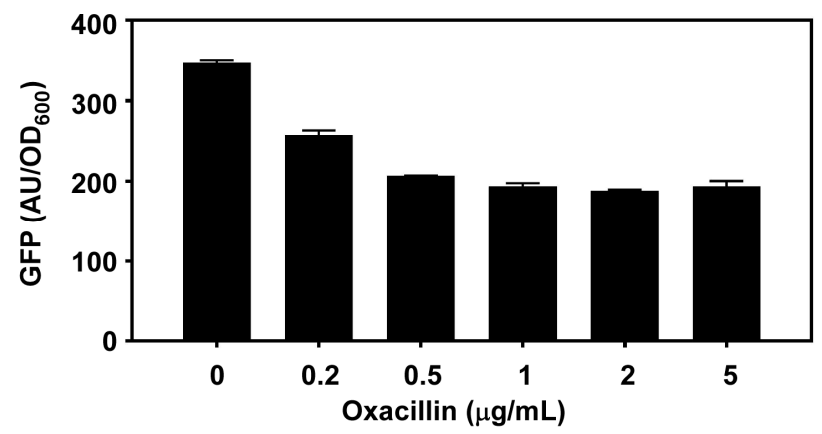

Figure A1. Effect of oxacillin on P1 promoter activity. Staphylococcus aureus USA300 carrying P1-GFP reporter plasmid [42] was grown in $150 \mu \mathrm{L}$ TSB at $37{ }^{\circ} \mathrm{C}$ until mid-exponential growth phase. After addition of oxacillin to the concentration indicated, the culture was further incubated for $2 \mathrm{~h}$ at $37^{\circ} \mathrm{C}$, and $\mathrm{OD}_{600}$ and GFP expression were measured (Enspire, Perkin Elmer, Waltham, MA, USA). AU, arbitrary unit.

\section{References}

1. Lowy, F.D. Staphylococcus aureus infections. N. Engl. J. Med. 1998, 339, 520-532. [CrossRef] [PubMed]

2. Gordon, R.J.; Lowy, F.D. Pathogenesis of methicillin-resistant Staphylococcus aureus infection. Clin. Infect. Dis. 2008, 46, S350-S359. [CrossRef] [PubMed]

3. Recsei, P.; Kreiswirth, B.; O'Reilly, M.; Schlievert, P.; Gruss, A.; Novick, R.P. Regulation of exoprotein gene expression in Staphylococcus aureus by agr. Mol. Gen. Genet. 1986, 202, 58-61. [CrossRef] [PubMed]

4. Xiong, Y.Q.; Willard, J.; Yeaman, M.R.; Cheung, A.L.; Bayer, A.S. Regulation of Staphylococcus aureus $\alpha$-toxin gene (hla) expression by agr, sarA, and sae in vitro and in experimental infective endocarditis. J. Infect. Dis. 2006, 194, 1267-1275. [CrossRef] [PubMed]

5. Cheung, G.Y.; Joo, H.S.; Chatterjee, S.S.; Otto, M. Phenol-soluble modulins-Critical determinants of staphylococcal virulence. FEMS Microbiol. Rev. 2014, 38, 698-719. [CrossRef] [PubMed]

6. Cheung, A.L.; Nishina, K.A.; Trotonda, M.P.; Tamber, S. The SarA protein family of Staphylococcus aureus. Int. J. Biochem. Cell Biol. 2008, 40, 355-361. [CrossRef] [PubMed]

7. Novick, R.P.; Geisinger, E. Quorum sensing in staphylococci. Annu. Rev. Genet. 2008, 42, 541-564. [CrossRef] [PubMed]

8. $\quad$ Liang, X.; Zheng, L.; Landwehr, C.; Lunsford, D.; Holmes, D.; Ji, Y. Global regulation of gene expression by ArlRS, a two-component signal transduction regulatory system of Staphylococcus aureus. J. Bacteriol. 2005, 187, 5486-5492. [CrossRef] [PubMed]

9. Yarwood, J.M.; McCormick, J.K.; Schlievert, P.M. Identification of a novel two-component regulatory system that acts in global regulation of virulence factors of Staphylococcus aureus. J. Bacteriol. 2001, 183, 1113-1123. [CrossRef] [PubMed]

10. Kong, C.; Neoh, H.M.; Nathan, S. Targeting Staphylococcus aureus toxins: A potential form of anti-virulence therapy. Toxins 2016. [CrossRef] [PubMed]

11. Bronner, S.; Monteil, H.; Prevost, G. Regulation of virulence determinants in Staphylococcus aureus: Complexity and applications. FEMS Microbiol. Rev. 2004, 28, 183-200. [CrossRef] [PubMed] 
12. Giraudo, A.T.; Raspanti, C.G.; Calzolari, A.; Nagel, R. Characterization of a Tn551-mutant of Staphylococcus aureus defective in the production of several exoproteins. Can. J. Microbiol. 1994, 40, 677-681. [CrossRef] [PubMed]

13. Giraudo, A.T.; Calzolari, A.; Cataldi, A.A.; Bogni, C.; Nagel, R. The sae locus of Staphylococcus aureus encodes a two-component regulatory system. FEMS Microbiol. Lett. 1999, 177, 15-22. [CrossRef] [PubMed]

14. Geiger, T.; Goerke, C.; Mainiero, M.; Kraus, D.; Wolz, C. The virulence regulator sae of Staphylococcus aureus: Promoter activities and response to phagocytosis-related signals. J. Bacteriol. 2008, 190, 3419-3428. [CrossRef] [PubMed]

15. Novick, R.P.; Jiang, D. The staphylococcal saeRS system coordinates environmental signals with agr quorum sensing. Microbiology 2003, 149, 2709-2717. [CrossRef] [PubMed]

16. Arya, R.; Princy, S.A. Exploration of modulated genetic circuits governing virulence determinants in Staphylococcus aureus. Indian. J. Microbiol. 2016, 56, 19-27. [CrossRef] [PubMed]

17. Haag, A.F.; Bagnoli, F. The role of two-component signal transduction systems in Staphylococcus aureus virulence regulation. Curr. Top. Microbiol. Immunol. 2016. [CrossRef]

18. Jeong, D.W.; Cho, H.; Lee, H.; Li, C.; Garza, J.; Fried, M.; Bae, T. Identification of P3 promoter and distinct roles of the two promoters of the SaeRS two-component system in Staphylococcus aureus. J. Bacteriol. 2011, 193, 4672-4684. [CrossRef] [PubMed]

19. Steinhuber, A.; Goerke, C.; Bayer, M.G.; Doring, G.; Wolz, C. Molecular architecture of the regulatory locus sae of Staphylococcus aureus and its impact on expression of virulence factors. J. Bacteriol. 2003, 185, 6278-6286. [CrossRef] [PubMed]

20. Li, D.; Cheung, A. The repression of hla by Rot is dependent on sae in Staphylococcus aureus. Infect. Immun. 2008, 76, 1068-1075. [CrossRef] [PubMed]

21. Mainiero, M.; Goerke, C.; Geiger, T.; Gonser, C.; Herbert, S.; Wolz, C. Differential target gene activation by the Staphylococcus aureus two-component system saeRS. J. Bacteriol. 2010, 192, 613-623. [CrossRef] [PubMed]

22. Jeong, D.W.; Cho, H.; Jones, M.B.; Shatzkes, K.; Sun, F.; Ji, Q.; Liu, Q.; Peterson, S.N.; He, C.; Bae, T. The auxiliary protein complex SaePQ activates the phosphatase activity of sensor kinase SaeS in the SaeRS two-component system of Staphylococcus aureus. Mol. Microbiol. 2012, 86, 331-348. [CrossRef] [PubMed]

23. Liu, Q.; Cho, H.; Yeo, W.S.; Bae, T. The extracytoplasmic linker peptide of the sensor protein SaeS tunes the kinase activity required for staphylococcal virulence in response to host signals. PLoS Pathog. 2015, 11, e1004799. [CrossRef] [PubMed]

24. Adhikari, R.P.; Novick, R.P. Regulatory organization of the staphylococcal sae locus. Microbiology 2008, 154, 949-959. [CrossRef] [PubMed]

25. Mascher, T. Intramembrane-sensing histidine kinases: A new family of cell envelope stress sensors in firmicutes bacteria. FEMS Microbiol. Lett. 2006, 264, 133-144. [CrossRef] [PubMed]

26. Mascher, T. Bacterial (intramembrane-sensing) histidine kinases: Signal transfer rather than stimulus perception. Trends. Microbiol. 2014, 22, 559-565. [CrossRef] [PubMed]

27. Schafer, D.; Lam, T.T.; Geiger, T.; Mainiero, M.; Engelmann, S.; Hussain, M.; Bosserhoff, A.; Frosch, M.; Bischoff, M.; Wolz, C.; et al. A point mutation in the sensor histidine kinase SaeS of Staphylococcus aureus strain Newman alters response to biocide exposure. J. Bacteriol. 2009, 191, 7306-7314. [CrossRef] [PubMed]

28. Flack, C.E.; Zurek, O.W.; Meishery, D.D.; Pallister, K.B.; Malone, C.L.; Horswill, A.R.; Voyich, J.M. Differential regulation of staphylococcal virulence by the sensor kinase SaeS in response to neutrophil-derived stimuli. Proc. Natl. Acad. Sci. USA 2014, 111, E2037-E2045. [CrossRef] [PubMed]

29. Vandenesch, F.; Kornblum, J.; Novick, R.P. A temporal signal, independent of agr, is required for hla but not spa transcription in Staphylococcus aureus. J. Bacteriol. 1991, 173, 6313-6320. [PubMed]

30. Wolz, C.; Pohlmann-Dietze, P.; Steinhuber, A.; Chien, Y.T.; Manna, A.; van Wamel, W.; Cheung, A. Agr-independent regulation of fibronectin-binding protein(s) by the regulatory locus sar in Staphylococcus aureus. Mol. Microbiol. 2000, 36, 230-243. [CrossRef] [PubMed]

31. Sun, F.; Li, C.; Jeong, D.; Sohn, C.; He, C.; Bae, T. In the Staphylococcus aureus two-component system sae, the response regulator SaeR binds to a direct repeat sequence and DNA binding requires phosphorylation by the sensor kinase SaeS. J. Bacteriol. 2010, 192, 2111-2127. [CrossRef] [PubMed]

32. Makgotlho, P.E.; Marincola, G.; Schafer, D.; Liu, Q.; Bae, T.; Geiger, T.; Wasserman, E.; Wolz, C.; Ziebuhr, W.; Sinha, B. SDS interferes with SaeS signaling of Staphylococcus aureus independently of SaePQ. PLoS ONE 2013, 8, e71644. [CrossRef] [PubMed] 
33. Olson, M.E.; Nygaard, T.K.; Ackermann, L.; Watkins, R.L.; Zurek, O.W.; Pallister, K.B.; Griffith, S.; Kiedrowski, M.R.; Flack, C.E.; Kavanaugh, J.S.; et al. Staphylococcus aureus nuclease is an SaeRS-dependent virulence factor. Infect. Immun. 2013, 81, 1316-1324. [CrossRef] [PubMed]

34. Ramundo, M.S.; Beltrame, C.O.; Botelho, A.M.; Coelho, L.R.; Silva-Carvalho, M.C.; Ferreira-Carvalho, B.T.; Nicolas, M.F.; Guedes, I.A.; Dardenne, L.E.; O'Gara, J.; et al. A unique SaeS allele overrides cell-density dependent expression of saeR and lukSF-PV in the ST30-SCCmecIV lineage of CA-MRSA. Int. J. Med. Microbiol. 2016. [CrossRef] [PubMed]

35. Fan, X.; Zhang, X.; Zhu, Y.; Niu, L.; Teng, M.; Sun, B.; Li, X. Structure of the DNA-binding domain of the response regulator SaeR from Staphylococcus aureus. Acta. Crystallogr. D Biol. Crystallogr. 2015, 71, 1768-1776. [CrossRef] [PubMed]

36. Ko, T.P.; Huang, C.Y.; Hsieh, T.J.; Chen, S.C.; Chen, Y.R.; Yang, C.S.; Kuo, H.C.; Wang, W.L.; Hsiao, T.H.; Lin, C.H.; et al. Crystal structures of staphylococcal SaeR reveal possible DNA-binding modes. Biochem. Biophys. Res. Commun. 2016. [CrossRef] [PubMed]

37. Nygaard, T.K.; Pallister, K.B.; Ruzevich, P.; Griffith, S.; Vuong, C.; Voyich, J.M. SaeR binds a consensus sequence within virulence gene promoters to advance USA300 pathogenesis. J. Infect. Dis. 2010, 201, 241-254. [CrossRef] [PubMed]

38. Joiner, K.A.; Ganz, T.; Albert, J.; Rotrosen, D. The opsonizing ligand on Salmonella Typhimurium influences incorporation of specific, but not azurophil, granule constituents into neutrophil phagosomes. J. Cell Biol. 1989, 109, 2771-2782. [CrossRef] [PubMed]

39. Benson, M.A.; Lilo, S.; Nygaard, T.; Voyich, J.M.; Torres, V.J. Rot and SaeRS cooperate to activate expression of the staphylococcal superantigen-like exoproteins. J. Bacteriol. 2012, 194, 4355-4365. [CrossRef] [PubMed]

40. Zurek, O.W.; Nygaard, T.K.; Watkins, R.L.; Pallister, K.B.; Torres, V.J.; Horswill, A.R.; Voyich, J.M. The role of innate immunity in promoting SaeR/S-mediated virulence in Staphylococcus aureus. J. Innate. Immun. 2014, 6, 21-30. [CrossRef] [PubMed]

41. Eisenhauer, P.B.; Lehrer, R.I. Mouse neutrophils lack defensins. Infect. Immun. 1992, 60, 3446-3447. [PubMed]

42. Cho, H.; Jeong, D.W.; Liu, Q.; Yeo, W.S.; Vogl, T.; Skaar, E.P.; Chazin, W.J.; Bae, T. Calprotectin increases the activity of the SaeRS two component system and murine mortality during Staphylococcus aureus infections. PLoS Pathog. 2015, 11, e1005026. [CrossRef] [PubMed]

43. Foell, D.; Wittkowski, H.; Vogl, T.; Roth, J. S100 proteins expressed in phagocytes: A novel group of damage-associated molecular pattern molecules. J. Leukoc. Biol. 2007, 81, 28-37. [CrossRef] [PubMed]

44. Gebhardt, C.; Nemeth, J.; Angel, P.; Hess, J. S100A8 and S100A9 in inflammation and cancer. Biochem. Pharmacol. 2006, 72, 1622-1631. [CrossRef] [PubMed]

45. Corbin, B.D.; Seeley, E.H.; Raab, A.; Feldmann, J.; Miller, M.R.; Torres, V.J.; Anderson, K.L.; Dattilo, B.M.; Dunman, P.M.; Gerads, R.; et al. Metal chelation and inhibition of bacterial growth in tissue abscesses. Science 2008, 319, 962-965. [CrossRef] [PubMed]

46. Kehl-Fie, T.E.; Chitayat, S.; Hood, M.I.; Damo, S.; Restrepo, N.; Garcia, C.; Munro, K.A.; Chazin, W.J.; Skaar, E.P. Nutrient metal sequestration by calprotectin inhibits bacterial superoxide defense, enhancing neutrophil killing of Staphylococcus aureus. Cell Host Microbe 2011, 10, 158-164. [CrossRef] [PubMed]

47. Ohlsen, K.; Ziebuhr, W.; Koller, K.P.; Hell, W.; Wichelhaus, T.A.; Hacker, J. Effects of subinhibitory concentrations of antibiotics on $\alpha$-toxin $(h l a)$ gene expression of methicillin-sensitive and methicillin-resistant Staphylococcus aureus isolates. Antimicrob. Agents Chemother. 1998, 42, 2817-2823. [PubMed]

48. Kuroda, H.; Kuroda, M.; Cui, L.; Hiramatsu, K. Subinhibitory concentrations of $\beta$-lactam induce haemolytic activity in Staphylococcus aureus through the SaeRS two-component system. FEMS Microbiol. Lett. 2007, 268, 98-105. [CrossRef] [PubMed]

49. Hanada, Y.; Sekimizu, K.; Kaito, C. Silkworm apolipophorin protein inhibits Staphylococcus aureus virulence. J. Biol. Chem. 2011, 286, 39360-39369. [CrossRef] [PubMed]

50. Omae, Y.; Hanada, Y.; Sekimizu, K.; Kaito, C. Silkworm apolipophorin protein inhibits hemolysin gene expression of Staphylococcus aureus via binding to cell surface lipoteichoic acids. J. Biol. Chem. 2013, 288, 25542-25550. [CrossRef] [PubMed]

51. Weinrick, B.; Dunman, P.M.; McAleese, F.; Murphy, E.; Projan, S.J.; Fang, Y.; Novick, R.P. Effect of mild acid on gene expression in Staphylococcus aureus. J. Bacteriol. 2004, 186, 8407-8423. [CrossRef] [PubMed] 
52. Neumann, Y.; Ohlsen, K.; Donat, S.; Engelmann, S.; Kusch, H.; Albrecht, D.; Cartron, M.; Hurd, A.; Foster, S.J. The effect of skin fatty acids on Staphylococcus aureus. Arch. Microbiol. 2015, 197, 245-267. [CrossRef] [PubMed]

53. Schmitt, J.; Joost, I.; Skaar, E.P.; Herrmann, M.; Bischoff, M. Haemin represses the haemolytic activity of Staphylococcus aureus in an Sae-dependent manner. Microbiology 2012, 158, 2619-2631. [CrossRef] [PubMed]

54. Baker, J.; Sitthisak, S.; Sengupta, M.; Johnson, M.; Jayaswal, R.K.; Morrissey, J.A. Copper stress induces a global stress response in Staphylococcus aureus and represses sae and agr expression and biofilm formation. Appl. Environ. Microbiol. 2010, 76, 150-160. [CrossRef] [PubMed]

55. Blickwede, M.; Goethe, R.; Wolz, C.; Valentin-Weigand, P.; Schwarz, S. Molecular basis of florfenicol-induced increase in adherence of Staphylococcus aureus strain Newman. J. Antimicrob. Chemother. 2005, 56, 315-323. [CrossRef] [PubMed]

56. Li, N.; Luo, M.; Fu, Y.J.; Zu, Y.G.; Wang, W.; Zhang, L.; Yao, L.P.; Zhao, C.J.; Sun, Y. Effect of corilagin on membrane permeability of Escherichia coli, Staphylococcus aureus and candida albicans. Phytother. Res. 2012, 27, 1517-1523. [PubMed]

57. Qiu, J.; Wang, D.; Xiang, H.; Feng, H.; Jiang, Y.; Xia, L.; Dong, J.; Lu, J.; Yu, L.; Deng, X. Subinhibitory concentrations of thymol reduce enterotoxins A and B and $\alpha$-hemolysin production in Staphylococcus aureus isolates. PLoS ONE 2010, 5, e9736. [CrossRef] [PubMed]

58. Parsons, J.B.; Kukula, M.; Jackson, P.; Pulse, M.; Simecka, J.W.; Valtierra, D.; Weiss, W.J.; Kaplan, N.; Rock, C.O. Perturbation of Staphylococcus aureus gene expression by the enoyl-acyl carrier protein reductase inhibitor AFN-1252. Antimicrob. Agents Chemother. 2013, 57, 2182-2190. [CrossRef] [PubMed]

59. Saleh, F.A.; Freer, J.H. Inhibition of secretion of staphylococcal alpha toxin by cerulenin. J. Med. Microbiol. 1984, 18, 205-216. [CrossRef] [PubMed]

60. Bernardo, K.; Pakulat, N.; Fleer, S.; Schnaith, A.; Utermohlen, O.; Krut, O.; Muller, S.; Kronke, M. Subinhibitory concentrations of linezolid reduce Staphylococcus aureus virulence factor expression. Antimicrob. Agents Chemother. 2004, 48, 546-555. [CrossRef] [PubMed]

61. Jenkins, R.; Burton, N.; Cooper, R. Proteomic and genomic analysis of methicillin-resistant Staphylococcus aureus (MRSA) exposed to manuka honey in vitro demonstrated down-regulation of virulence markers. J. Antimicrob. Chemother. 2014, 69, 603-615. [CrossRef] [PubMed]

62. Lee, J.H.; Park, J.H.; Cho, M.H.; Lee, J. Flavone reduces the production of virulence factors, staphyloxanthin and $\alpha$-hemolysin, in Staphylococcus aureus. Curr. Microbiol. 2012, 65, 726-732. [CrossRef] [PubMed]

63. Cho, H.; Jeong, D.W.; Li, C.; Bae, T. Organizational requirements of the SaeS binding sites for a functional P1 promoter of the sae operon in Staphylococcus aureus. J. Bacteriol. 2012, 194, 2865-2876. [CrossRef] [PubMed]

64. Giraudo, A.T.; Cheung, A.L.; Nagel, R. The sae locus of Staphylococcus aureus controls exoprotein synthesis at the transcriptional level. Arch. Microbiol. 1997, 168, 53-58. [CrossRef] [PubMed]

65. Liang, X.; Yu, C.; Sun, J.; Liu, H.; Landwehr, C.; Holmes, D.; Ji, Y. Inactivation of a two-component signal transduction system, SaeRS, eliminates adherence and attenuates virulence of Staphylococcus aureus. Infect. Immun. 2006, 74, 4655-4665. [CrossRef] [PubMed]

66. Rogasch, K.; Ruhmling, V.; Pane-Farre, J.; Hoper, D.; Weinberg, C.; Fuchs, S.; Schmudde, M.; Broker, B.M.; Wolz, C.; Hecker, M.; et al. Influence of the two-component system SaeRS on global gene expression in two different Staphylococcus aureus strains. J. Bacteriol. 2006, 188, 7742-7758. [CrossRef] [PubMed]

67. Pantrangi, M.; Singh, V.K.; Wolz, C.; Shukla, S.K. Staphylococcal superantigen-like genes, ssl5 and ssl8, are positively regulated by Sae and negatively by Agr in the Newman strain. FEMS Microbiol. Lett. 2010, 308, 175-184. [CrossRef] [PubMed]

68. Harraghy, N.; Homerova, D.; Herrmann, M.; Kormanec, J. Mapping the transcription start points of the Staphylococcus aureus eap, emp, and $v w b$ promoters reveals a conserved octanucleotide sequence that is essential for expression of these genes. J. Bacteriol. 2008, 190, 447-451. [CrossRef] [PubMed]

69. Johnson, M.; Cockayne, A.; Morrissey, J.A. Iron-regulated biofilm formation in Staphylococcus aureus Newman requires ica and the secreted protein emp. Infect. Immun. 2008, 76, 1756-1765. [CrossRef] [PubMed]

70. Rooijakkers, S.H.; Ruyken, M.; van Roon, J.; van Kessel, K.P.; van Strijp, J.A.; van Wamel, W.J. Early expression of SCIN and CHIPS drives instant immune evasion by Staphylococcus aureus. Cell Microbiol. 2006, 8, 1282-1293. [CrossRef] [PubMed] 
71. Dumont, A.L.; Nygaard, T.K.; Watkins, R.L.; Smith, A.; Kozhaya, L.; Kreiswirth, B.N.; Shopsin, B.; Unutmaz, D.; Voyich, J.M.; Torres, V.J. Characterization of a new cytotoxin that contributes to Staphylococcus aureus pathogenesis. Mol. Microbiol. 2011, 79, 814-825. [CrossRef] [PubMed]

72. Ventura, C.L.; Malachowa, N.; Hammer, C.H.; Nardone, G.A.; Robinson, M.A.; Kobayashi, S.D.; DeLeo, F.R. Identification of a novel Staphylococcus aureus two-component leukotoxin using cell surface proteomics. PLOS ONE 2010, 5, e11634. [CrossRef] [PubMed]

73. Baroja, M.L.; Herfst, C.A.; Kasper, K.J.; Xu, S.X.; Gillett, D.A.; Li, J.; Reid, G.; McCormick, J.K. The SaeRS two-component system is a direct and dominant transcriptional activator of toxic shock syndrome toxin-1 in Staphylococcus aureus. J. Bacteriol. 2016, 198, 2732-2742. [CrossRef] [PubMed]

74. Cassat, J.E.; Hammer, N.D.; Campbell, J.P.; Benson, M.A.; Perrien, D.S.; Mrak, L.N.; Smeltzer, M.S.; Torres, V.J.; Skaar, E.P. A secreted bacterial protease tailors the Staphylococcus aureus virulence repertoire to modulate bone remodeling during osteomyelitis. Cell Host Microbe 2013, 13, 759-772. [CrossRef] [PubMed]

75. Luong, T.T.; Sau, K.; Roux, C.; Sau, S.; Dunman, P.M.; Lee, C.Y. Staphylococcus aureus ClpC divergently regulates capsule via sae and $\operatorname{cod} Y$ in strain Newman but activates capsule via $\operatorname{cod} Y$ in strain UAMS-1 and in strain Newman with repaired saeS. J. Bacteriol. 2011, 193, 686-694. [CrossRef] [PubMed]

76. Goerke, C.; Fluckiger, U.; Steinhuber, A.; Zimmerli, W.; Wolz, C. Impact of the regulatory loci agr, sarA and sae of Staphylococcus aureus on the induction of alpha-toxin during device-related infection resolved by direct quantitative transcript analysis. Mol. Microbiol. 2001, 40, 1439-1447. [CrossRef] [PubMed]

77. Novick, R.P. Autoinduction and signal transduction in the regulation of staphylococcal virulence. Mol. Microbiol. 2003, 48, 1429-1449. [CrossRef] [PubMed]

78. Queck, S.Y.; Jameson-Lee, M.; Villaruz, A.E.; Bach, T.H.; Khan, B.A.; Sturdevant, D.E.; Ricklefs, S.M.; Li, M.; Otto, M. RnaIII-independent target gene control by the agr quorum-sensing system: Insight into the evolution of virulence regulation in Staphylococcus aureus. Mol. Cell 2008, 32, 150-158. [CrossRef] [PubMed]

79. Johnson, M.; Sengupta, M.; Purves, J.; Tarrant, E.; Williams, P.H.; Cockayne, A.; Muthaiyan, A.; Stephenson, R.; Ledala, N.; Wilkinson, B.J.; et al. Fur is required for the activation of virulence gene expression through the induction of the sae regulatory system in staphylococcus aureus. Int. J. Med. Microbiol. 2011, 301, 44-52. [CrossRef] [PubMed]

80. Giraudo, A.T.; Mansilla, C.; Chan, A.; Raspanti, C.; Nagel, R. Studies on the expression of regulatory locus sae in Staphylococcus aureus. Curr. Microbiol. 2003, 46, 246-250. [CrossRef] [PubMed]

81. Wolz, C.; McDevitt, D.; Foster, T.J.; Cheung, A.L. Influence of agr on fibrinogen binding in Staphylococcus aureus Newman. Infect. Immun. 1996, 64, 3142-3147. [PubMed]

82. Saravia-Otten, P.; Muller, H.P.; Arvidson, S. Transcription of Staphylococcus aureus fibronectin binding protein genes is negatively regulated by agr and an agr-independent mechanism. J. Bacteriol. 1997, 179, 5259-5263. [PubMed]

83. Dassy, B.; Hogan, T.; Foster, T.J.; Fournier, J.M. Involvement of the accessory gene regulator (agr) in expression of type 5 capsular polysaccharide by Staphylococcus aureus. J. Gen. Microbiol. 1993, 139, 1301-1306. [CrossRef] [PubMed]

84. Luong, T.; Sau, S.; Gomez, M.; Lee, J.C.; Lee, C.Y. Regulation of Staphylococcus aureus capsular polysaccharide expression by agr and sarA. Infect. Immun. 2002, 70, 444-450. [CrossRef] [PubMed]

85. Dinges, M.M.; Orwin, P.M.; Schlievert, P.M. Exotoxins of Staphylococcus aureus. Clin. Microbiol. Rev. 2000, 13, 16-34. [CrossRef] [PubMed]

86. Novick, R.P.; Ross, H.F.; Projan, S.J.; Kornblum, J.; Kreiswirth, B.; Moghazeh, S. Synthesis of staphylococcal virulence factors is controlled by a regulatory RNA molecule. EMBO J. 1993, 12, 3967-3975. [PubMed]

87. Dubrac, S.; Msadek, T. Identification of genes controlled by the essential YycG/YycF two-component system of Staphylococcus aureus. J. Bacteriol. 2004, 186, 1175-1181. [CrossRef] [PubMed]

88. Dubrac, S.; Boneca, I.G.; Poupel, O.; Msadek, T. New insights into the WalK/WalR (YycG/YycF) essential signal transduction pathway reveal a major role in controlling cell wall metabolism and biofilm formation in Staphylococcus aureus. J. Bacteriol. 2007, 189, 8257-8269. [CrossRef] [PubMed]

89. Delaune, A.; Dubrac, S.; Blanchet, C.; Poupel, O.; Mader, U.; Hiron, A.; Leduc, A.; Fitting, C.; Nicolas, P.; Cavaillon, J.M.; et al. The WalKR system controls major staphylococcal virulence genes and is involved in triggering the host inflammatory response. Infect. Immun. 2012, 80, 3438-3453. [CrossRef] [PubMed] 
90. Hecker, M.; Reder, A.; Fuchs, S.; Pagels, M.; Engelmann, S. Physiological proteomics and stress/starvation responses in Bacillus subtilis and Staphylococcus aureus. Res. Microbiol. 2009, 160, 245-258. [CrossRef] [PubMed]

91. Chen, H.Y.; Chen, C.C.; Fang, C.S.; Hsieh, Y.T.; Lin, M.H.; Shu, J.C. Vancomycin activates $\sigma$ B in vancomycin-resistant Staphylococcus aureus resulting in the enhancement of cytotoxicity. PLoS ONE 2011, 6, e24472. [CrossRef] [PubMed]

92. Mitchell, G.; Fugere, A.; Pepin Gaudreau, K.; Brouillette, E.; Frost, E.H.; Cantin, A.M.; Malouin, F. SigB is a dominant regulator of virulence in Staphylococcus aureus small-colony variants. PLoS ONE 2013, 8, e65018. [CrossRef] [PubMed]

93. Bischoff, M.; Dunman, P.; Kormanec, J.; Macapagal, D.; Murphy, E.; Mounts, W.; Berger-Bachi, B.; Projan, S. Microarray-based analysis of the Staphylococcus aureus $\sigma$ B regulon. J. Bacteriol. 2004, 186, 4085-4099. [CrossRef] [PubMed]

94. Nicholas, R.O.; Li, T.; McDevitt, D.; Marra, A.; Sucoloski, S.; Demarsh, P.L.; Gentry, D.R. Isolation and characterization of a $\operatorname{sig} B$ deletion mutant of Staphylococcus aureus. Infect Immun 1999, 67, 3667-3669. [PubMed]

95. Miyazaki, E.; Chen, J.M.; Ko, C.; Bishai, W.R. The Staphylococcus aureus rsbw (orf159) gene encodes an anti-sigma factor of SigB. J. Bacteriol. 1999, 181, 2846-2851. [PubMed]

96. Romilly, C.; Lays, C.; Tomasini, A.; Caldelari, I.; Benito, Y.; Hammann, P.; Geissmann, T.; Boisset, S.; Romby, P.; Vandenesch, F. A non-coding RNA promotes bacterial persistence and decreases virulence by regulating a regulator in Staphylococcus aureus. PLoS Pathog. 2014, 10, e1003979. [CrossRef] [PubMed]

97. Goerke, C.; Fluckiger, U.; Steinhuber, A.; Bisanzio, V.; Ulrich, M.; Bischoff, M.; Patti, J.M.; Wolz, C. Role of Staphylococcus aureus global regulators sae and sigmaB in virulence gene expression during device-related infection. Infect. Immun. 2005, 73, 3415-3421. [CrossRef] [PubMed]

98. Lee, J.W.; Helmann, J.D. Functional specialization within the Fur family of metalloregulators. Biometals 2007, 20, 485-499. [CrossRef] [PubMed]

99. Hantke, K. Regulation of ferric iron transport in Escherichia coli K12: Isolation of a constitutive mutant. Mol. Gen. Genet. 1981, 182, 288-292. [CrossRef] [PubMed]

100. Litwin, C.M.; Calderwood, S.B. Cloning and genetic analysis of the Vibrio vulnificus fur gene and construction of a fur mutant by in vivo marker exchange. J. Bacteriol. 1993, 175, 706-715. [PubMed]

101. Johnson, M.; Cockayne, A.; Williams, P.H.; Morrissey, J.A. Iron-responsive regulation of biofilm formation in Staphylococcus aureus involves fur-dependent and fur-independent mechanisms. J. Bacteriol. 2005, 187, 8211-8215. [CrossRef] [PubMed]

102. Horsburgh, M.J.; Ingham, E.; Foster, S.J. In Staphylococcus aureus, fur is an interactive regulator with PerR, contributes to virulence, and is necessary for oxidative stress resistance through positive regulation of catalase and iron homeostasis. J. Bacteriol. 2001, 183, 468-475. [CrossRef] [PubMed]

103. Richardson, A.R.; Dunman, P.M.; Fang, F.C. The nitrosative stress response of Staphylococcus aureus is required for resistance to innate immunity. Mol. Microbiol. 2006, 61, 927-939. [CrossRef] [PubMed]

104. McNamara, P.J.; Milligan-Monroe, K.C.; Khalili, S.; Proctor, R.A. Identification, cloning, and initial characterization of rot, a locus encoding a regulator of virulence factor expression in Staphylococcus aureus. J. Bacteriol. 2000, 182, 3197-3203. [CrossRef] [PubMed]

105. Parsons, J.B.; Broussard, T.C.; Bose, J.L.; Rosch, J.W.; Jackson, P.; Subramanian, C.; Rock, C.O. Identification of a two-component fatty acid kinase responsible for host fatty acid incorporation by Staphylococcus aureus. Proc. Natl. Acad. Sci. USA 2014, 111, 10532-10537. [CrossRef] [PubMed]

106. McCleary, W.R.; Stock, J.B. Acetyl phosphate and the activation of two-component response regulators. J. Biol. Chem. 1994, 269, 31567-31572. [PubMed]

107. Otto, M. Staphylococcal infections: Mechanisms of biofilm maturation and detachment as critical determinants of pathogenicity. Annu. Rev. Med. 2013, 64, 175-188. [CrossRef] [PubMed]

108. Mack, D.; Fischer, W.; Krokotsch, A.; Leopold, K.; Hartmann, R.; Egge, H.; Laufs, R. The intercellular adhesin involved in biofilm accumulation of Staphylococcus epidermidis is a linear $\beta$-1,6-linked glucosaminoglycan: Purification and structural analysis. J. Bacteriol. 1996, 178, 175-183. [PubMed]

109. Maira-Litran, T.; Kropec, A.; Abeygunawardana, C.; Joyce, J.; Mark, G., 3rd; Goldmann, D.A.; Pier, G.B. Immunochemical properties of the staphylococcal poly-N-acetylglucosamine surface polysaccharide. Infect. Immun. 2002, 70, 4433-4440. 
110. O'Gara, J.P. Ica and beyond: Biofilm mechanisms and regulation in Staphylococcus epidermidis and Staphylococcus aureus. FEMS Microbiol. Lett. 2007, 270, 179-188. [CrossRef] [PubMed]

111. Paharik, A.E.; Horswill, A.R. The staphylococcal biofilm: Adhesins, regulation, and host response. Microbiol. Spectr. 2016. [CrossRef]

112. Lim, Y.; Jana, M.; Luong, T.T.; Lee, C.Y. Control of glucose- and NaCl-induced biofilm formation by rbf in Staphylococcus aureus. J. Bacteriol. 2004, 186, 722-729. [CrossRef] [PubMed]

113. Zapotoczna, M.; McCarthy, H.; Rudkin, J.K.; O'Gara, J.P.; O'Neill, E. An essential role for coagulase in Staphylococcus aureus biofilm development reveals new therapeutic possibilities for device-related infections. J. Infect. Dis. 2015, 212, 1883-1893. [CrossRef] [PubMed]

114. Cue, D.; Lei, M.G.; Lee, C.Y. Genetic regulation of the intercellular adhesion locus in staphylococci. Front. Cell. Infect. Microbiol. 2012. [CrossRef] [PubMed]

115. Gotz, F. Staphylococcus and biofilms. Mol. Microbiol. 2002, 43, 1367-1378. [CrossRef] [PubMed]

116. Boles, B.R.; Horswill, A.R. Agr-mediated dispersal of Staphylococcus aureus biofilms. PLoS Pathog. 2008, 4, e1000052. [CrossRef] [PubMed]

117. Cue, D.; Junecko, J.M.; Lei, M.G.; Blevins, J.S.; Smeltzer, M.S.; Lee, C.Y. SaeRS-dependent inhibition of biofilm formation in Staphylococcus aureus Newman. PLoS ONE 2015, 10, e0123027. [CrossRef] [PubMed]

118. O'Neill, E.; Pozzi, C.; Houston, P.; Humphreys, H.; Robinson, D.A.; Loughman, A.; Foster, T.J.; O'Gara, J.P. A novel Staphylococcus aureus biofilm phenotype mediated by the fibronectin-binding proteins, FnBPA and FnBPB. J. Bacteriol. 2008, 190, 3835-3850. [CrossRef] [PubMed]

119. McCourt, J.; O'Halloran, D.P.; McCarthy, H.; O'Gara, J.P.; Geoghegan, J.A. Fibronectin-binding proteins are required for biofilm formation by community-associated methicillin-resistant Staphylococcus aureus strain lac. FEMS Microbiol. Lett. 2014, 353, 157-164. [CrossRef] [PubMed]

120. Caiazza, N.C.; O'Toole, G.A. $\alpha$-Toxin is required for biofilm formation by Staphylococcus aureus. J. Bacteriol. 2003, 185, 3214-3217. [CrossRef] [PubMed]

121. Huseby, M.J.; Kruse, A.C.; Digre, J.; Kohler, P.L.; Vocke, J.A.; Mann, E.E.; Bayles, K.W.; Bohach, G.A.; Schlievert, P.M.; Ohlendorf, D.H.; et al. Beta toxin catalyzes formation of nucleoprotein matrix in staphylococcal biofilms. Proc. Natl. Acad. Sci. USA 2010, 107, 14407-14412. [CrossRef] [PubMed]

122. Beenken, K.E.; Blevins, J.S.; Smeltzer, M.S. Mutation of sarA in Staphylococcus aureus limits biofilm formation. Infect. Immun. 2003, 71, 4206-4211. [CrossRef] [PubMed]

123. O’Neill, E.; Pozzi, C.; Houston, P.; Smyth, D.; Humphreys, H.; Robinson, D.A.; O'Gara, J.P. Association between methicillin susceptibility and biofilm regulation in Staphylococcus aureus isolates from device-related infections. J. Clin. Microbiol. 2007, 45, 1379-1388. [CrossRef] [PubMed]

124. Mrak, L.N.; Zielinska, A.K.; Beenken, K.E.; Mrak, I.N.; Atwood, D.N.; Griffin, L.M.; Lee, C.Y.; Smeltzer, M.S. SaeRS and sarA act synergistically to repress protease production and promote biofilm formation in Staphylococcus aureus. PLoS ONE 2012, 7, e38453. [CrossRef] [PubMed]

125. McDonald, B.; Urrutia, R.; Yipp, B.G.; Jenne, C.N.; Kubes, P. Intravascular neutrophil extracellular traps capture bacteria from the bloodstream during sepsis. Cell Host Microbe 2012, 12, 324-333. [CrossRef] [PubMed]

126. Berends, E.T.; Horswill, A.R.; Haste, N.M.; Monestier, M.; Nizet, V.; von Kockritz-Blickwede, M. Nuclease expression by Staphylococcus aureus facilitates escape from neutrophil extracellular traps. J Innate. Immun. 2010, 2, 576-586. [CrossRef] [PubMed]

127. Munzenmayer, L.; Geiger, T.; Daiber, E.; Schulte, B.; Autenrieth, S.E.; Fraunholz, M.; Wolz, C. Influence of Sae and Agr regulated factors on the escape of Staphylococcus aureus from human macrophages. Cell Microbiol. 2016. [CrossRef] [PubMed]

128. Nygaard, T.K.; Pallister, K.B.; Zurek, O.W.; Voyich, J.M. The impact of $\alpha$-toxin on host cell plasma membrane permeability and cytokine expression during human blood infection by CA-MRSA USA300. J. Leukoc. Biol. 2013, 94, 971-979. [CrossRef] [PubMed]

129. Watkins, R.L.; Pallister, K.B.; Voyich, J.M. The SaeR/S gene regulatory system induces a pro-inflammatory cytokine response during Staphylococcus aureus infection. PLoS ONE 2011, 6, e19939. [CrossRef] [PubMed]

130. Miyazaki, S.; Matsumoto, Y.; Sekimizu, K.; Kaito, C. Evaluation of Staphylococcus aureus virulence factors using a silkworm model. FEMS Microbiol. Lett. 2012, 326, 116-124. [CrossRef] [PubMed] 
131. Bae, T.; Banger, A.K.; Wallace, A.; Glass, E.M.; Aslund, F.; Schneewind, O.; Missiakas, D.M. Staphylococcus aureus virulence genes identified by bursa aurealis mutagenesis and nematode killing. Proc. Natl. Acad. Sci. USA 2004, 101, 12312-12317. [CrossRef] [PubMed]

132. Voyich, J.M.; Vuong, C.; Dewald, M.; Nygaard, T.K.; Kocianova, S.; Griffith, S.; Jones, J.; Iverson, C.; Sturdevant, D.E.; Braughton, K.R.; et al. The SaeR/S gene regulatory system is essential for innate immune evasion by Staphylococcus aureus. J. Infect. Dis. 2009, 199, 1698-1706. [CrossRef] [PubMed]

133. Montgomery, C.P.; Boyle-Vavra, S.; Daum, R.S. Importance of the global regulators Agr and SaeRS in the pathogenesis of CA-MRSA USA300 infection. PLoS ONE 2010, 5, e15177. [CrossRef] [PubMed]

134. Beenken, K.E.; Mrak, L.N.; Zielinska, A.K.; Atwood, D.N.; Loughran, A.J.; Griffin, L.M.; Matthews, K.A.; Anthony, A.M.; Spencer, H.J.; Post, G.R.; et al. Impact of the functional status of SaeRS on in vivo phenotypes of Staphylococcus aureus sarA mutants. Mol. Microbiol. 2014, 92, 1299-1312. [CrossRef] [PubMed]

135. Kernbauer, E.; Maurer, K.; Torres, V.J.; Shopsin, B.; Cadwell, K. Gastrointestinal dissemination and transmission of Staphylococcus aureus following bacteremia. Infect. Immun. 2015, 83, 372-378. [CrossRef] [PubMed]

136. Handke, L.D.; Rogers, K.L.; Olson, M.E.; Somerville, G.A.; Jerrells, T.J.; Rupp, M.E.; Dunman, P.M.; Fey, P.D. Staphylococcus epidermidis SaeR is an effector of anaerobic growth and a mediator of acute inflammation. Infect. Immun. 2008, 76, 141-152. [CrossRef] [PubMed]

137. Ravcheev, D.A.; Best, A.A.; Tintle, N.; Dejongh, M.; Osterman, A.L.; Novichkov, P.S.; Rodionov, D.A. Inference of the transcriptional regulatory network in Staphylococcus aureus by integration of experimental and genomics-based evidence. J. Bacteriol. 2011, 193, 3228-3240. [CrossRef] [PubMed]

(C) 2016 by the authors; licensee MDPI, Basel, Switzerland. This article is an open access article distributed under the terms and conditions of the Creative Commons Attribution (CC-BY) license (http:/ / creativecommons.org/licenses/by/4.0/). 